\title{
Effect and correlation of testing load and specimen's thickness on the hardness and percent depth of cure of condensable composite resins
}

\author{
Ibrahim Mohamed Hamouda ${ }^{1,2 *}$ and Majed Abudllah Mohammed Almalki ${ }^{3}$ \\ ${ }^{1}$ College of Dentistry, Umm Alqurra University, Makkah, Saudi Arabia \\ ${ }^{2}$ Faculty of Dentistry, Mansoura University, Mansoura, Egypt \\ ${ }^{3}$ College of Dentistry, Umm Alqurra University, Makkah, Saudi Arabia
}

\begin{abstract}
Background: Dental condensable composite resins were used as a substitute for dental amalgam to restore posterior teeth. They were be condensed as dental amalgam, which made it easier to produce an accurate proximal teeth contact.

Objectives: The aim of this study was to measure the top and bottom hardness of two condensable composites at different thicknesses (2,3,4 and 5 mm) at different loads (25,50 and $100 \mathrm{gf})$. Percent depth of cure was calculated for both materials at the different thicknesses. The correlation between the hardness and percent depth of cure was calculated.

Materials and methods: The materials used were Glacier and SureFil condensable composite resins. 120 specimens were prepared from both composite resins, 60 specimens each using transparent Perspex molds of $4 \mathrm{~mm}$ diameter and thicknesses of 2,3,4,5 mm. Specimens of each composite resin were divided into 4 groups corresponding to the different thicknesses, 15 specimens for each thickness. Specimens for each thickness were further divided into 3 subgroups, 5 specimens for each load applied during hardness testing (25,50 and 100gf). The hardness was measured using a universal micro hardness testing machine for the top and bottom surfaces of each specimen. Percent depth of cure was calculated by dividing the bottom hardness value by the top hardness value and multiplied by 100 . Also, the correlation between the hardness and percent depth of cure was calculated.

Results: The results indicated that, the top hardness values were greater than that of the bottom hardness values for both composite resins. Glacier composite showed that, the hardness was increased by increasing the testing loads and decreased by increasing the thickness, except at $3 \mathrm{~mm}$ thickness of Glacier, which showed higher hardness than $2 \mathrm{~mm}$ thickness. Also, SureFil composite resin showed increased hardness values by increasing the testing loads and decreased by increasing the thickness. The hardness of $3 \mathrm{~mm}$ thickness was greater than that of $2 \mathrm{~mm}$ thickness. The percent depth of cure in $2 \mathrm{~mm}$ and $3 \mathrm{~mm}$ thicknesses were more than $80 \%$, while the other thicknesses showed percent depth of cure less than $80 \%$. Both materials showed high positive correlation between the hardness and percent depth of cure.

Conclusions: The top hardness was greater than that of the bottom hardness. The hardness of $3 \mathrm{~mm}$ thickness was greater than that of $2 \mathrm{~mm}$ thickness. The hardness was increased by increasing the testing loads and decreased by increasing the thickness. The percent depth of cure was decreased by increasing thickness. There was high positive correlation between the hardness and percent depth of cure.
\end{abstract}

\section{Introduction}

Composite resin restorative materials was introduced to the dental field to replace dental amalgam because of better esthetics. These restorative resins were subjected to intensive changes in its compositions to overcome the drawbacks of this class of dental biomaterials to improve its strength and polymerization shrinkage. There were several classes of composite resins such as conventional, microfilled, hybrid, nanofilled composite resins and finally the condensable or packable composite resins were introduced to be condensed directly into the cavity to restore posterior teeth.

Introduction of several new condensable composite resins resulted in rapid popularity of this class of dental materials. This new technology was developed by Lars Ehrnford of Sweden in 1995. This type of materials is composed of a resin matrix and an inorganic ceramic filler. This filler structure was consisted of aluminum oxide and silicon dioxide glass particles or barium aluminum silicate or strontium glasses. This composite resin has a unique properties because the resin is incorporated into the fibrous ceramic filler structure [1].

Condensable composite resins are designed to be used in areas that are subjected to greater stresses such as posterior restorations. The condensable composites has good handling properties such as the application technique that is similar to amalgam. The physiological

*Correspondence to: Ibrahim Mohamed Hamouda, College of dentistry, Umm alqura University, Makah, Saudi Arabia, Tel. 00966537924044; E-mail: IMHamouda@uqu.edu.sa

Key words: composite resins, condensable composites, hardness, curing thickness, hardness loading, percent depth of cure

Received: June 27, 2020; Accepted: July 23, 2020; Published: July 29, 2020 
interproximal contacts in class II restorations could be reproduced easily using of matrix bands and wedges. The condensable composites has showed good physical and mechanical properties and superior handling characteristics [2].

Manufacturers demonstrated bulk placement of condensable composite resins because they have low polymerization shrinkage which resulted from increased filler loading. The conventional hybrid composites should be applied incrementally and cured in $2 \mathrm{~mm}$ thickness only, while condensable composite resins could be cured up to $5 \mathrm{~mm}$ depth [3].

Previous studies demonstrated that the fracture resistance of weakened teeth restored with packable resin composite have been similar of sound teeth [4]. Other researches demonstrated that the marginal adaptation and polymerization shrinkage of bulk-fill flow able composite resins showed significantly less polymerization stresses than that of the conventional flowable composites [5]. The indenter load had a statistically significant effect on the measured hardness of composite specimens and it could produce a fails results if not selected carefully. Hardness tests could be classified on the type of indentation load into macro hardness, micro hardness and nanohardness. Microhardness testers (Vickers, Knops) use applied loads ranging from $1 \mathrm{gf}$ to $1 \mathrm{kgf}$ [6]. On the other hand, there were a limited number of studies regarding the condensable composite resins. Therefore, the present study was conducted to measure the top and bottom hardness of two condensable composites at different thicknesses and different loads. Percent depth of cure was calculated for both materials at the different thicknesses. The correlation between the hardness and percent depth of cure was calculated.

\section{Materials and methods}

The materials used in this study were two condensable composite resins, (1) Glacier (Southern Dental Industries Limited, Australia). It is a radiopaque, light cured, microfilled-hybrid composite resin, shade A2 and (2) SureFil (Dentsply Caulk, Lakeview \& Clark Avenues, Milford, DE 19963-0359, USA). It is a high-density posterior restorative, hybrid composite, radiopaque, light-cured, highly viscous and packable consistency. Shade A was used because SureFil composite resin was supplied in shades of A, B and C.

\section{Hardness test}

For the hardness test, 120 specimens were prepared from both Glacier and SureFil composite resin materials, 60 specimens each.
Specimens were prepared using transparent Perspex moulds of $4 \mathrm{~mm}$ diameter with different thicknesses of 2,3,4,5 mm. specimens of each material were divided into 4 groups, 15 specimens for each specimen thickness, further, divided into 3 subgroups, 5 specimens for each applied load from the micro-hardness tester during testing. The material was condensed into the mould, covered with celluloid strip and cured for 40 seconds from one side only, which assigned as the top surface. The tip of the curing unit was placed immediately over the transparent strip (zero distance). After curing, specimens were removed from their moulds and stored in deionized water at $37^{\circ} \mathrm{C}$ for 24 hours. Top and bottom hardness were measured using microhardness tester (FM, Future Tech Corp. Tokyo, Japan.). The applied load on the indenter of the micro-hardness tester was 25,50 and $100 \mathrm{gf}$ for 5 seconds. The dimensions of the indentation made by the testing machine was automatically measured to calculate the Vickers hardness number (VHN). Three readings were made for each surface to get the mean value of the hardness for each surface. These values were then averaged for the five specimens to obtain a mean top surface hardness values and a bottom surface hardness values. The bottom hardness values were divided by the top hardness values and multiplied by 100 to obtain percentage depth of cure. If that mean hardness value exceeded $80 \%$, the specimen was considered to be adequately polymerized [6].

\section{Statistical analysis}

The data were collected and tabulated for statistical analysis. Twoway ANOVA was used to detect the significance through the tested groups for the hardness test and percent depth of cure. When significant effects were detected, least significance difference test (LSD) was used to determine the significant differences between groups at the level of significance $\mathrm{p} \leq 0.05$.

\section{Hardness test:}

The results of the hardness test of Glacier composite resin are presented in Table 1. Two-way ANOVA showed highly significant differences between the hardness values of the different thicknesses and loads $(\mathrm{P}<0.001)$. The interactions of thicknesses and applied loads were not statistically significant $(\mathrm{P}>0.05)$. The statistical analysis of the results were highly significant among the top and bottom surfaces hardness values $(\mathrm{P}<0.001)$. The interactions of different thicknesses and surfaces were highly significant $(\mathrm{P}<0.001)$. The interactions of different loads and surfaces, also between loads, thicknesses and surfaces were not significantly different $(\mathrm{P}>0.05)$. The statistical analysis of the results showed significant differences between top and bottom hardness values

Table 1. Top and bottom hardness for Glacier composite resin at different loads and thicknesses (VHN)

\begin{tabular}{|c|c|c|c|c|c|c|c|}
\hline \multirow{2}{*}{ Thickness } & \multicolumn{2}{|c|}{25 gf } & \multicolumn{2}{|c|}{50 gf } & \multicolumn{2}{|c|}{100 gf } & \multirow{2}{*}{$\begin{array}{c}\text { Average } \\
\pm \text { SD }\end{array}$} \\
\hline & $\begin{array}{c}\text { Top } \\
\text { Mean } \pm \text { SD }\end{array}$ & $\begin{array}{c}\text { Bottom } \\
\text { Mean } \pm \text { SD }\end{array}$ & $\begin{array}{c}\text { Top } \\
\text { Mean } \pm \text { SD }\end{array}$ & $\begin{array}{c}\text { Bottom } \\
\text { Mean } \pm \text { SD }\end{array}$ & $\begin{array}{c}\text { Top } \\
\text { Mean } \pm \text { SD }\end{array}$ & $\begin{array}{c}\text { Bottom } \\
\text { Mean } \pm \text { SD }\end{array}$ & \\
\hline $2 \mathrm{~mm}$ & $33.7^{\mathrm{fgh}} \pm 3.8$ & $27.0^{\mathrm{lm}} \pm 1.9$ & $36.7^{\mathrm{cdef}} \pm 4.2$ & $29.9^{\mathrm{j} \mathrm{jk} 1} \pm 3.2$ & $42.4^{\mathrm{a}} \pm 2.3$ & $32.3^{\text {ghij }} \pm 2.8$ & $33.58^{\mathrm{AB}} \pm 5.05$ \\
\hline $3 \mathrm{~mm}$ & $35.0^{\mathrm{efg}} \pm 3.3$ & $28.2^{\mathrm{klm}} \pm 3.2$ & $38.7^{\mathrm{abcd}} \pm 4.3$ & $31.2^{\mathrm{hijk}} \pm 3.4$ & $40.6^{\mathrm{ab}} \pm 3.5$ & $35.0^{\mathrm{efg}} \pm 4.0$ & $34.8^{\mathrm{A}} \pm 5.38$ \\
\hline $4 \mathrm{~mm}$ & $33.6^{\mathrm{fgh}} \pm 3.0$ & $25.7^{\mathrm{m}} \pm 2.1$ & $36.5^{\text {defg }} \pm 2.7$ & $28.8^{\mathrm{jklm}} \pm 2.0$ & $39.9^{\mathrm{abc}} \pm 2.2$ & $33.5^{\mathrm{fghi}} \pm 2.4$ & $32.83^{\mathrm{B}} \pm 5.13$ \\
\hline $5 \mathrm{~mm}$ & $32.3^{\mathrm{ghij}} \pm 3.4$ & $17.9^{\mathrm{n}} \pm 1.8$ & $37.6^{\text {bcde }} \pm 2.2$ & $26.5^{\mathrm{Im}} \pm 2.1$ & $39.0^{\mathrm{abcd}} \pm 2.8$ & $30.1^{\text {hijkl }} \pm 2.9$ & $30.54^{\mathrm{C}} \pm 4.39$ \\
\hline Average \pm SD & \multicolumn{2}{|c|}{$27.79^{\mathrm{C}} \pm 7.79$} & \multicolumn{2}{|c|}{$31.75^{\mathrm{B}} \pm 6.33$} & \multicolumn{2}{|c|}{$35.26^{\mathrm{A}} \pm 7.69$} & \\
\hline
\end{tabular}

Values with same superscripts are not significantly different.

F-value 39.59

$\mathrm{P}$-value $\mathrm{P}<0.001$

LSD 1.5 
at each applied load. There were significant differences between different thicknesses and loads particularly the bottom surfaces $(\mathrm{P}<0.001)$.

The results of the hardness test of SureFil composite resin are presented in Table 2. Two-way ANOVA showed significant differences among the different thicknesses, loads and surfaces $(\mathrm{P}<0.001)$. The interactions of thicknesses and applied loads were significantly different $(\mathrm{P}<0.05)$. The interactions of thicknesses and surfaces, and applied loads and surfaces were highly significant $(\mathrm{P}<0.001)$. The interactions of thicknesses, loads and surfaces were not significantly different $(\mathrm{P}>0.05)$. LSD test showed significant differences among the different applied loads, surfaces and thicknesses.

\section{Percent depth of cure}

The mean percent depth of cure for Glacier and SureFil composite resin materials are presented in Tables 3 and 4 . The statistical analysis of the results showed highly significant differences between different thicknesses and applied loads $(\mathrm{P}<0.001)$. The interactions of the applied loads and different thicknesses were highly significant $(\mathrm{P}<0.001)$. The percent depth of cure was above $80 \%$ when the material applied in $2 \mathrm{~mm}$ or $3 \mathrm{~mm}$ thickness except for SureFil at $25 \mathrm{gf}$. More than $3 \mathrm{~mm}$ thickness, the percent depth of cure was less than $80 \%$. The material can be considered adequately polymerized when the percent depth of cure was greater than $80 \%$. The highest mean percent depth of cure was

Table 2. Top and bottom hardness for SureFil composite resin at different loads and thicknesses (VHN)

\begin{tabular}{|c|c|c|c|c|c|c|c|}
\hline \multirow{2}{*}{ Thickness } & \multicolumn{2}{|c|}{$25 \mathrm{gf}$} & \multicolumn{2}{|c|}{50 gf } & \multicolumn{2}{|c|}{100 gf } & \multirow{2}{*}{$\begin{array}{l}\text { Average } \\
\quad \pm \text { SD }\end{array}$} \\
\hline & $\begin{array}{c}\text { Top } \\
\text { Mean } \pm \text { SD }\end{array}$ & $\begin{array}{c}\text { Bottom } \\
\text { Mean } \pm \text { SD }\end{array}$ & $\begin{array}{c}\text { Top } \\
\text { Mean } \pm \text { SD }\end{array}$ & $\begin{array}{c}\text { Bottom } \\
\text { Mean } \pm \text { SD }\end{array}$ & $\begin{array}{c}\text { Top } \\
\text { Mean } \pm \text { SD }\end{array}$ & $\begin{array}{c}\text { Bottom } \\
\text { Mean } \pm \text { SD }\end{array}$ & \\
\hline $2 \mathrm{~mm}$ & $38.1^{\mathrm{efg}} \pm 2.4$ & $26.3^{\mathrm{ij}} \pm 2.1$ & $40.8^{\text {bcdef }} \pm 3.1$ & $38.2^{\operatorname{defg}} \pm 3.3$ & $44.1^{\mathrm{ab}} \pm 3.4$ & $41.3^{\text {bcde }} \pm 2.7$ & $\begin{array}{l}38.14^{\mathrm{A}} \\
\pm 6.33\end{array}$ \\
\hline $3 \mathrm{~mm}$ & $36.5^{\mathrm{g}} \pm 3.1$ & $25.7^{\mathrm{ijk}} \pm 2.5$ & $40.2^{\text {cdefg }} \pm 3.5$ & $38.0^{\text {efg }} \pm 1.9$ & $45.2^{\mathrm{a}} \pm 3.4$ & $42.0^{\mathrm{abcd}} \pm 3.4$ & $37.85^{\mathrm{A}} \pm 7.0$ \\
\hline $4 \mathrm{~mm}$ & $37.3^{\mathrm{fg}} \pm 2.7$ & $22.0^{\mathrm{kl}} \pm 2.5$ & $37.9^{\mathrm{efg}} \pm 3.9$ & $30.6^{\mathrm{h}} \pm 2.6$ & $43.8^{\mathrm{abc}} \pm 4.8$ & $31.9^{h} \pm 3.0$ & $33.93^{\mathrm{B}} \pm 7.61$ \\
\hline $5 \mathrm{~mm}$ & $36.8^{\mathrm{g}} \pm 3.7$ & $19.8^{1} \pm 2.3$ & $38.6^{\mathrm{defg}} \pm 2.4$ & $22.9^{9^{\mathrm{kl}} \pm 2.5}$ & $42.9^{\mathrm{abc}} \pm 3.5$ & $28.3^{\mathrm{hi}} \pm 2.7$ & $31.54^{\mathrm{C}} \pm 8.99$ \\
\hline Average $\pm \mathrm{SD}$ & \multicolumn{2}{|c|}{$30.25^{c} \pm 7.68$} & \multicolumn{2}{|c|}{$35.9^{\mathrm{B}} \pm 6.39$} & \multicolumn{2}{|c|}{$39.94^{\mathrm{A}} \pm 6.69$} & \\
\hline
\end{tabular}

Values with same superscripts are not significantly different.

F-value 32.99

$\mathrm{P}$-value $\mathrm{P}<0.001$

LSD 1.6

Table 3. Percent depth of cure for Glacier composite resin

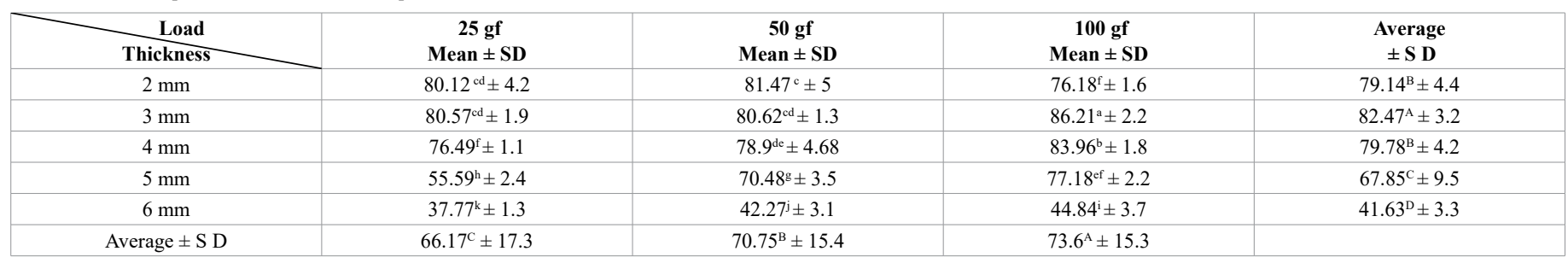

Values with same superscripts are not significantly different.

F-value 293.8

$\mathrm{P}$-value $\mathrm{P}<0.001$

LSD 1.29

Table 4. Percent depth of cure for SureFil composite resin

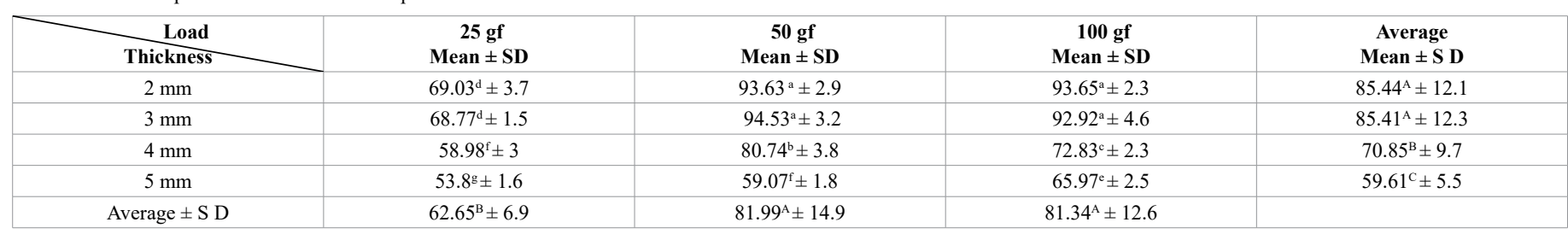

Values with same superscripts are not significantly different.

F-value 229.9

$\mathrm{P}$-value $\mathrm{P}<0.001$

LSD 1.05

Table 5. Correlation coefficient between the hardness and percent depth of cure of both composite resins

\begin{tabular}{|c|c|c|}
\hline Materials & Variables & Hardness \\
\hline \multirow{2}{*}{ Glacier composite resin } & Hardness & Percent depth of cure \\
\cline { 2 - 3 } & Percent depth of cure & $0.505^{* *}$ \\
\hline \multirow{2}{*}{ SureFil composite resin } & Hardness & $0.711^{* *}$ \\
\cline { 2 - 3 }
\end{tabular}

* Positive correlation

** Highly positive correlation

+ Not significant 
recoded for both materials at $2 \mathrm{~mm}$ and $3 \mathrm{~mm}$ thickness. Both materials showed highly positive correlation between the hardness and percent depth of cure (Table 5).

\section{Discussion}

Composite placement is far more time-consuming and demanding. Composites cannot be packed vertically into a cavity in such a way that the material flows laterally as well as vertically to ensure intimate contact with the cavity walls. Condensable composites were developed by adjusting the filler distribution to increase the strength and stiffness of the uncured material and provide a consistency and handling characteristics similar to those of lathe-cut amalgam. Recently, several curing methods have been introduced to reduce the exposure times and/or greater depth of cure. These are highly desirable benefits that can greatly reduce restoration treatment time and associated cost to the patient. Increased intensity of the curing lamps allows shorter curing times or increased depth of cure [7].

Condensable composite resins may preferred by most clinician because of its easily handling characteristics than conventional resinbased composite resins. The physical properties of condensable composites were superior to those of micro filled composites but they aren't superior to small-particle hybrid composites [8].

In this study, composites of shades A2 for Glacier and A for SureFil and the curing time of 40 seconds because they are clinically relevant. Depth of cure and hardness of composite were studied because they are important and clinically relevant measures of the quality of curing of the condensable composite resins. The tip of the curing unit was placed directly over the transparent strip (zero distance) over the transparent celluloid strip on the molds to obtain the maximum intensity of the light and deepest curing depth. The larger the curing tips distance in relation to the composite, the lower the knops hardness values [9].

The data obtained from this test revealed that, the top hardness was greater than that of the bottom hardness regardless the thickness of the composite or the applied indenter load particularly at the increased depths. Previous research concluded that there were significant differences among the depths of the cured composite resins. The hardness at the top surface was significantly higher followed by the middle and bottom surfaces. This based on the average optical density of the condensable composite resins always increased as thickness increased which may affect its curing quality $[10,11]$.

The depth of cure is an important property for light-activated composite resins because insufficient curing of the deep part of the composite restoration may leads to increased releasing of monomer, decreased strength, stiffness, and insufficient bonding to the teeth [12]. There are several methods for testing of the depth of cure, such as scraping test [13], hardness and degree of conversion measurements [14], quantification of released monomers [15], penetrometer test [16], and discoloration test [17]. In this study, the percent depth of cure was determined by measurement of the top and bottom hardness of specimens. The bottom hardness was divided on the top hardness then multiplied by 100 to get the percent depth of cure.

The present study used 2,4- and 5-mm thicknesses for measurement of the hardness of Glacier and SureFil condensable composites because a previous study demonstrated that both materials could be cured for $5 \mathrm{~mm}$ thickness [18]. The influence of co-initiators in a composite and the effect of the wavelength of the light on the hardness are marked.
Light transmission in dental composite resins is high for the longer wavelength than for the shorter wavelength. This means that a high percentage of the shorter wavelengths is absorbed near the surface of the composite and cannot excite co-initiators in greater depth [19]. This explains why the higher load gives higher hardness than that of the lower load. The hardness values at the bottom were not significantly different from their top hardness values measured at the same time for 2 and $3 \mathrm{~mm}$ thicknesses. For 4 and $5 \mathrm{~mm}$ thick specimens, the hardness values at the bottom were significantly different from those at the top measured at the same time.

The results of this study showed reduction in bottom hardness with increased depth of the composite, except for $3 \mathrm{~mm}$ depth of glacier composite, which exhibited greater hardness than that of $2 \mathrm{~mm}$ depth. This finding might be due to the heat produced during polymerization which developed by double bonds conversion. The temperature rise is different between the different parts of the specimen. The deeper parts had higher temperature rise than that of the superficial parts because of the reduced heat conduction to the surroundings. Minimum increase in temperature may leads to significant increase in the hardness values. It was demonstrated that subsurface hardness would increase with increasing size of the polymerizing specimen. Also, the oxygen inhibition of polymerization may play an important role in this observation [20].

The results of this study showed increased hardness with increased applied load, in other words, $100 \mathrm{gf}$ of the indenter gives higher hardness than that of 50 or 25 gf. This may be explained by the smaller the load applied, the less indention produced by the indenter within the superior oxygen inhibition layer. Previous study indicated that the hardness number after using of $400 \mathrm{gf}$ as an indenter load was significantly greater than that of 200 gf. So, the load applied on the indenter has significant effect on the measured hardness and it could affect the accuracy of the results if it is not selected carefully [21]. Another study concluded that the superficial layer of the cured composite exhibited less degree of polymerization and reduced hardness less than that of the intermediate layer [22].

Both materials used in this study, showed highly positive correlation between the hardness and percent depth of cure. Previous study concluded that the higher hardness of a light cured composite resin is obtained slightly below the surface layer. This is due to high light transmission, no oxygen inhibition layer was present and pronounced heat built-up that occurs in this layer. Therefore, the results of this study explained the higher hardness with the higher load. This was due to the indenter with higher loads penetrate to the deeper layers in the used composite resins to reach layers of higher hardness. Therefore, a greater hardness values were measured with increased indenter loads than that of lower indenter loads [23].

Condensable fill composite showed lower Vickers hardness than incremental fill composite. The difference in the recorded hardness for both materials depends on the differences in the organic matrix and the filler content, type, size and shape [24]. The top surface hardness was greater than bottom surface hardness due to monomer reactivity and the refractive index mismatch between the filler and the resin matrix [25]. A previous study concluded that the microhardness of the condensable composite resin was higher than that of the nanofilled and hybrid composite resins. This may be due to the increased depth of cure of the condensable composite than the others. Good correlation was found between depth of cure and microhardness of these composites [26]. 
Glacier composite resin was adequately polymerized when placed in $2 \mathrm{~mm}$ or $3 \mathrm{~mm}$ thickness (percent depth of cure above $80 \%$ ). The percent depth of cure of glacier indicated that, the material was adequately polymerized at the surface and the deeper parts up to $3 \mathrm{~mm}$ thickness under the lower and higher loads. SureFil composite resin adequately polymerized when placed in $2 \mathrm{~mm}$ or $3 \mathrm{~mm}$ thickness (percent depth of cure above $80 \%$ ) under the higher loads. The percent depth of cure of SureFil indicated that, the material was adequately polymerized at the deeper parts up to $3 \mathrm{~mm}$ thickness to a greater extent than the surface layer. Three millimeter thickness exhibited the highest depth of cure for both materials to an even higher than that of $2 \mathrm{~mm}$ thickness. Both materials showed highly positive correlation between the hardness and the percent depth of cure.

Previous studies concluded that, condensable composite resin could be cured up to $4 \mathrm{~mm}$ with surface hardness ratio exceeded $80 \%$ which clinically acceptable. This ratio considered adequately cured composite resin $[27,28]$. Despite manufacturers' claims to the contrary, condensable composites have not yet proven to be an answer to the general need for highly wear-resistant, easily placed posterior resins with low curing shrinkage and a depth of cure greater than $2 \mathrm{~mm}$ [7]. The top hardness was higher than that of the bottom hardness particularly in deeper thicknesses. It was concluded that, the hardness was increased by increasing the applied load and decreased by increasing the thickness, except that for $3 \mathrm{~mm}$ thickness that appears harder than that of $2 \mathrm{~mm}$ thickness. 2 and $3 \mathrm{~mm}$ thicknesses adequately polymerized than $4 \mathrm{~mm}$ and $5 \mathrm{~mm}$ thicknesses. The percent depth of cure in $2 \mathrm{~mm}$ and $3 \mathrm{~mm}$ thicknesses were more than $80 \%$, while the other thicknesses showed percent depth of cure less than $80 \%$. Both materials showed highly positive correlation between the hardness and percent depth of cure.

\section{Clinical significance}

Although, condensable composite resins can be polymerized up to $5 \mathrm{~mm}$ thicknesses but still showed decreased bottom hardness and percent depth of cure when cured above $4 \mathrm{~mm}$ thickness.

\section{Conflicts of interest}

No.

\section{References}

1. Singh P, Kumar N, Singh R, Kiran K, Kumar S (2015) Overview and recent advances in composite resin: A review. Inter J Sci Study 3: 169-172.

2. El Gezawi, Al Harbi F (2012) Reliability of bonded MOD restorations in maxillary premolars: microleakage and cusp fracture resistance. Acta Stomatol Croat 46: 31-42.

3. Yeli M, Kidiyoor KH, Nain B, Kumar P (2010) Recent advances in composite resins - A review. J Oral Res Rev 2: 8-14.

4. Mondelli RF, Ishikiriama SK, Oliveira Filho O, Mondelli J (2009) Fracture resistance of weakened teeth restored with condensable resin with and without cusp coverage. $J$ Appl Oral Sci 17:161-165. [Crossref]

5. Roggendorf MJ, Krämer N, Appelt A, Naumann M, Frankenberger R (2011) Marginal quality of flowable 4-mm base vs. conventionally layered resin composite. $J$ Dent 39(10):643-7.

6. Alexander U, Christian M, Mills RW, Jandt KD (2003) The influence of storage and indenter load on the knops hardness of dental composites polymerized with LED and halogen technologies. Dent Mater J 29:96-109.

7. Anusavice KJ: Phillips Science of Dental Materials, $12^{\text {th }}$ ed.W.B. Saunders Company, Philadelphia, London, 2013: PP.283-284.
8. Cobb DS, MacGregor KM Vargas MA, Denehy GE (2000) The physical properties of pack able and conventional posterior resin-based composites: a comparison. J Am Dent Assoc 131:1610-1615.

9. Sobrinho LC, Almeida de Lima A, Consani S, Knowles JC (2000) Influence of curing tips distance on composite knops hardness values. Braz Dent $J$ 2000; 11:11-17.

10. Cavalcante LM, Peris AR, Amaral CM, Ambrosano GM, Pimenta LA (2003) Influence of polymerization technique on micro hardness and micro leakage of resin composite restorations. Oper Dent 28:200-206.

11. Graziottin LF, da Costa NP, da Silveira ID, Veeck EB (2002) Measurement of the optical density of pack able composites: comparison between direct and indirect digital systems. Pesqui Odontol Brasl 16:299-307. [Crossref]

12. Ferracane JL (1985) Correlation between hardness and degree of conversion during the setting of unfilled dental restorative resins. Dent Mater J 1: 11-14.

13. International Organization for Standardization. Polymer-based filling, restorative and luting materials. ISO 4049. International Organization for Standardization, Brussels, Belgium 2000.

14. Ferracane JL (1985) Correlation between hardness and degree of conversion during the setting reaction of unfilled dental restorative resins. Dent Mater J 63:1093-1102.

15. Gagliani M, Fadini L, Ritzmann JM (2002) Depth of cure efficacy of high-power curing devices vs. traditional halogen lamps. $J$ Adhes Dent 4: 41-47. [Crossref]

16. Shortall AC, Wilson HJ, Harrington E (1995) Depth of cure of radiation-activated composite restoratives-Influence of shade and opacity. J Oral Rehabil 22: 337-342. [Crossref]

17. De Gee AJ, Ten Harkel-Hagenaar E, Davidson CL (1994) Color dye for identification of incompletely cured composite resins. J Prosthet Dent 52: 626-631. [Crossref]

18. Hamouda IM, Almalki MA (2019) Evaluation and correlation of depth of cure and degree of conversion of bulk-fill Posterior restorative composite resins. $J$ Dentistry and Oral Maxillofacial Surgery 1: 1-4.

19. Alexander U, Christian M, Mills RW, Jandt KD (2003) The influence of storage and indenter load on the knops hardness of dental composites polymerized with LED and halogen technologies. Dent Mater J 29: 96-109.

20. Asmussen E, Peutzfeldt A (2003) Influence of specimen diameter on the relationship between subsurface depth and hardness of a light-cured resin composite. Eur J Oral Sci 111: 543-546. [Crossref]

21. Alexander U, Christian M, Mills RW, Jandt KD (2003) The influence of storage and indenter load on the knops hardness of dental composites polymerized with LED and halogen technologies. Dent Mater J 29: 96-109.

22. Asmussen E, Peutzfeldt A (2003) Influence of specimen diameter on the relationship between subsurface depth and hardness of a light-cured resin composite. Eur J Oral Sci 111: 543-546. [Crossref]

23. Watts DC, Amer OM, Combe SC (1987) Surface hardness development in light-cured composites. Dent Mater 3: 265-269.

24. Abed YA, Sabry HA, Alrobeigy NA (2015) Degree of conversion and surface hardness of bulk-fill composite versus incremental fill composite. Tanta Dental Journal 12: 7180 .

25. Shortall AC, Palin WM, Burtscher P (2008) Refractive index mismatch and monomer reactivity influence on composite curing depth. J Dent $R$ 87: 84-88.

26. El-Nawawy M, Koraitim L, Abouelatta O, Hegazi H (2012) Depth of Cure and Microhardness of Nanofilled, Packable and Hybrid Dental Composite Resins. American Journal of Biomedical Engineering 2(6): 241-250.

27. Ozyurt E, Kurt A, Yildirim H (2019) Evaluation of the Polymerization Depth of Bulk Fill Resin Composites Polymerized by Different Procedures: An In-Vitro Study. Clin Exp Health Sci 9; 304-309.

28. Almozainy M (2018) Microhardness of Flowable Bulk-Fill Composite Materials. $J$ Adv Med Dent Scie Res 6(5): 36-41. [Crossref]

Copyright: (C2020 Hamouda IM. This is an open-access article distributed under the terms of the Creative Commons Attribution License, which permits unrestricted use, distribution, and reproduction in any medium, provided the original author and source are credited. 